\title{
The Influences of Spectral Music on Slovenian Compositional Creativity in the Last Few Decades
}

Doctoral thesis The Influences of Spectral Music on Slovenian Compositional Creativity in the Last Few Decades seeks to provide answers to two sets of questions. The first set examines the definition of spectral music and its role in European history of music, while the second aims to prove the traces of spectral thinking in Slovenian music.

The term spectral music designates music in which all materials are derived from the acoustic properties of the sound. It is challenging to define the exact meaning of the term, since it offers several meaningful levels, in particular the aesthetics and musical thinking associated with it, as well as the cultural and historical context of a given moment. It is reasonable to outline a slightly broader spectral circle compared to that foregrounded in the most orthodox of definitions. The latter in fact consider only composers of L'Itinéraire group to be spectral, focusing in particular on Gérard Grisey and Tristan Murail. Other spectral composers are linked to the French ones by compositional and technical solutions which have resulted in a highly distinctive sonority. A related issue is the existence of spectral school of composition and postspectral category of younger composers. To determine the degree of proximity to spectral ideas spectral "indicators" are used. They represent aspects of spectral music as expected in the works of the majority of spectral composers, but not their contemporaries. With a set of such particular features associated with it spectral music can be defined quite accurately.

There are some composers working in Slovenia as well (Neville Hall, Steven Loy, Urška Pompe, Uroš Rojko and Larisa Vrhunc) who have been influenced by the ideas of spectral music. This is also corroborated by the findings of the theoretical, historical and analytical part of this research.

No group of composers has formed as a reaction to serialism in the post-war period; spectral music has managed to find its way to Slovenia through various individuals only at the turn of the last century. Their compositional profile, based primarily on their answers, indicates that these composers are all in some way closely related to other countries. Somewhat different paths have led them to spectral ideas.

Traditional tools could not be applied in the analysis of the studied works, because the pieces are not conceived on the basis of motivic work, functional harmony or codified formal schemes. Each organizational system is conformed to a particular compositional plan, and the balance between a respect to the system and an intuitive response to musical matter is always present.

With regard to the categories discussed in the present thesis, the work by Uroš Rojko could be classified among those on the outer edge of spectral circle composed simultaneously with the establishment of spectral music. It seems reasonable to include the 
MUZIKOLOŠKI ZBORNIK • MUSICOLOGICAL ANNUAL LIV/1

studied works by Neville Hall and Larisa Vrhunc in the post-spectral group, whereas the analysed works by Urška Pompe and Steven Loy reflect the image of the spectral school.

Defended on 12 October 2017 at Faculty of Arts, University of Ljubljana. 